\title{
Cross-Roll Flow Forming of ODS Alloy Heat Exchanger Tubes For Hoop Creep Enhancement
}

\section{Quarterly Technical Progress Report Apr $1^{\text {st } 2004-J u n ~} 30^{\text {th }} 2004$}

\author{
Principal Investigator:
}

\section{Bimal K. Kad}

Department of Structural Engineering

University of California-San Diego, La Jolla, CA 92093-0411

Tel: (858) 534 7059; Fax: (858) 534-6373; e-mail: bkad@ucsd.edu

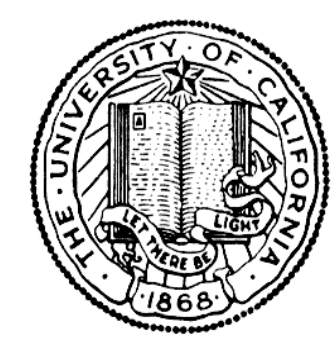

Issue Date August $31^{\text {st }} 2004$

National Energy Technology Laboratory

Contract Award: DE-FC26-03NT41985

For

Development of Technologies and Capabilities for

Developing Coal, Oil and Gas Energy Resources 
This report was prepared as an account of work sponsored by an agency of the United States Government. Neither the United States Government nor any agency thereof, nor any of their employees, makes any warranty, expressed or implied, or assumes any legal liability or responsibility for the accuracy, completeness, or usefulness of any information, apparatus, product, or process disclosed, or represents that its use would not infringe privately owned rights. Reference herein to any specific commercial product, process, or service by trade name, trademark, manufacturer, or otherwise, does not necessarily constitute or imply its endorsement, recommendation, or favoring by the United States Government or any agency thereof. The views and opinions of authors expressed herein do not necessarily state or reflect those of the United States Government or any agency thereof. 


\title{
Cross-Roll Flow Forming of ODS Alloy Heat Exchanger Tubes For Hoop Creep Enhancement
}

\begin{abstract}
Mechanically alloyed oxide dispersion strengthened (ODS) Fe-Cr-Al alloy thin walled tubes and sheets, produced via powder processing and consolidation methodologies, are promising materials for eventual use at temperatures up to $1200^{\circ} \mathrm{C}$ in the power generation industry, far above the temperature capabilities of conventional alloys. Target end-uses range from gas turbine combustor liners to high aspect ratio (L/D) heat exchanger tubes. Grain boundary creep processes at service temperatures, particularly those acting in the hoop direction, are the dominant failure mechanisms for such components. The processed microstructure of ODS alloys consists of high aspect ratio grains aligned parallel to the tube axis, a result of dominant axial metal flow which aligns the dispersoid particles and other impurities in the longitudinal direction. The dispersion distribution is unaltered on a micro scale by recrystallization thermal treatments, but the high aspect ratio grain shape typically obtained limits transverse grain spacing and consequently the hoop creep response. Improving hoop creep in ODS-alloy components will require understanding and manipulating the factors that control the recrystallization behavior, and represents a critical materials design and development challenge that must be overcome in order to fully exploit the potential of ODS alloys.

The objectives of this program are to 1) increase creep-strength at temperature in ODS-alloy tube and liner components by $100 \%$ via, 2) preferential cross-roll flow forming and grain/particle fibering in the critical hoop direction. Recent studies in crossrolled ODS-alloy sheets (produced from flattened tubes) indicate that transverse creep is significantly enhanced via controlled transverse grain fibering, and similar improvements are expected for cross-rolled tubes. The research program outlined here is iterative in nature and is intended to systematically i) prescribe extrusion consolidation methodologies via detailed test matrices, ii) examine and identify post-extrusion forming methodologies to create hoop strengthened tubes, which will be iii) evaluated at 'inservice' loads at service temperatures and environments. This research program is being conducted in collaboration with the DOE's Oak Ridge National Laboratory and the vested industrial partner Special Metals Corporation. In this performance period, program activities are continued in Task 2 and initiated in Task 3 and 4 as reported herein. The completion of Task 1 in the prior performance period ensures sufficient materials are available for the remainder of this program.
\end{abstract}




\title{
Cross-Roll Flow Forming of ODS Alloy Heat Exchanger Tubes For Hoop Creep Enhancement
}

\author{
Table of Contents
}

1. Executive Summary 1

2. Experimental Task Structure 3

3. Experimental Program Activity 3

4. Results and Discussion 4

5. Conclusions 5

6. References 5 


\section{§ 1. Executive Summary}

Oxide dispersion strengthened (ODS) ferritic alloys based on $\mathrm{FeCrAl}$ and intermetallic $\mathrm{Fe} 3 \mathrm{Al}$ alloys are promising materials for high-temperature, high-pressure tubing, liner and shell applications on account of their creep strength at very high temperatures and excellent corrosion resistance in oxidizing, oxidizing/sulphidizing and oxidizing/chlorinating environments compared to available high-temperature alloys. Requirements for such a combination of properties are found in advanced systems being developed for utilization of fossil fuels, such as the DOE's Vision 21 and FutureGen programs and in improved gas turbines being developed for power generation.

The creep strength of conventional high-temperature alloys decreases rapidly with increasing temperature, as shown in Fig. 1, since the thermodynamic stability of the various available strengthening phases also decreases with increasing temperature ${ }^{1}$. Also shown in Fig. 1 is the significant increase in temperature capability afforded when a dispersion of inert oxide particles is used as the strengthening phase. A major feature of oxide dispersion-strengthened alloys is that the most successful route for their preparation appears to involve powder metallurgical processing $^{2-6}$. Further, the critical need to maintain the fine size, volume fraction, and uniform distribution of the oxide particles in the alloy matrix, as well as the need to develop specific grain shapes, results in some significant differences in alloy fabricability and in the application of joining procedures, compared to conventional cast and wrought alloys. Hence, while ODS alloys offer a significant increase in temperature capability, they have a limited formability envelope, their mechanical properties are very anisotropic, and they cannot be joined by conventional fusion welding processes. Thus, the exploitation of the full capabilities of ODS alloys is limited until these critical hurdles are addressed and overcome.

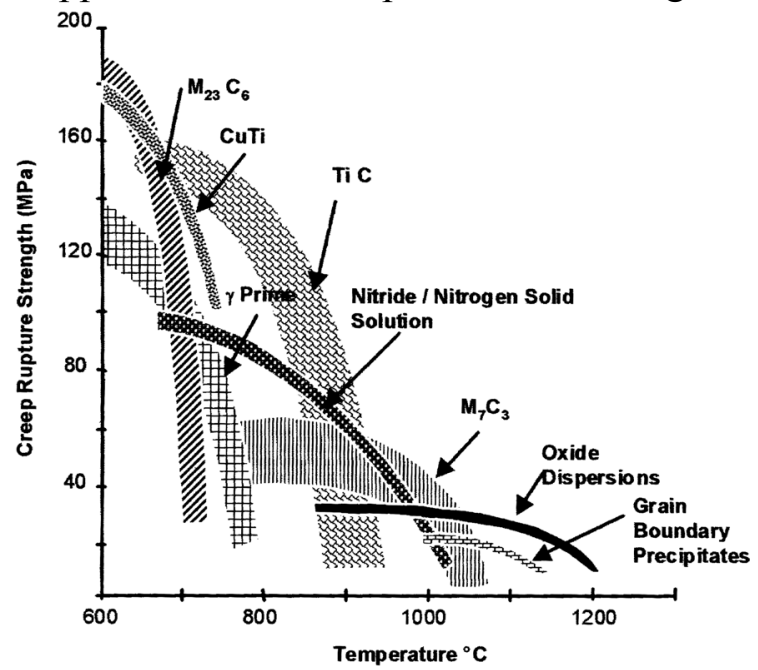

Figure 1. The creep performance envelope as a function of strengthening phase [1].

Our current program target is envisaged as a demonstration of the applicability of ferritic and $\mathrm{Fe}_{3} \mathrm{Al}$-based ODS alloys in the high temperature heat-exchanger tubing as proposed under the proposed DOE and NETL Vision-21 program metrics, intended to sustain internal pressures (P) of up to $1000 \mathrm{psi}$ at service temperatures of $1000-1200^{\circ} \mathrm{C}$. Within the framework of this target application, the development of suitable mechanically alloyed ferritic FeCrAl and intermetallic $\mathrm{Fe}_{3} \mathrm{Al}$ alloy materials and processes must strive to deliver a combination of high mechanical strength at temperature and prolonged creep-life in service. Such design requirements are often at odds with each other as strengthening measures severely limit the as-processed grain size detrimental to creep life. The extrusion consolidation processes currently employed cause material flow in the longitudinal direction, resulting in extreme dispersoid and powder surface impurity fibering in the axial direction in ODS materials. Thus, elongated grains are produced aligned parallel to the longitudinal direction, with a fine grain spacing in the hoop direction. The 
basic problem of limited hoop creep is illustrated in Figure 2a,b within the context of the existing underlying grain structure. Fortunately ODS-alloys do exhibit intrinsic creep strength sufficient to meet design requirements albeit that this performance is only exhibited in the longitudinal direction. Ultimate failure in transverse (hoop) creep involves creep cavity concentration, Figure $2 \mathrm{~b}$, which strongly depends on the dominant grain boundary orientation with respect to the loading axis, Figure $4{ }^{7}$. Such fibering, unless altered by post-flow forming, is expected to thwart attempts to arrive at the large transverse grain size ${ }^{3,8}$ considered essential for improved creep performance in the hoop direction. Clearly what is required is to devise a means of effecting material flow in directions other than longitudinal that would reorient the primary fibering axis of dispersoids and impurities in the hoop direction.

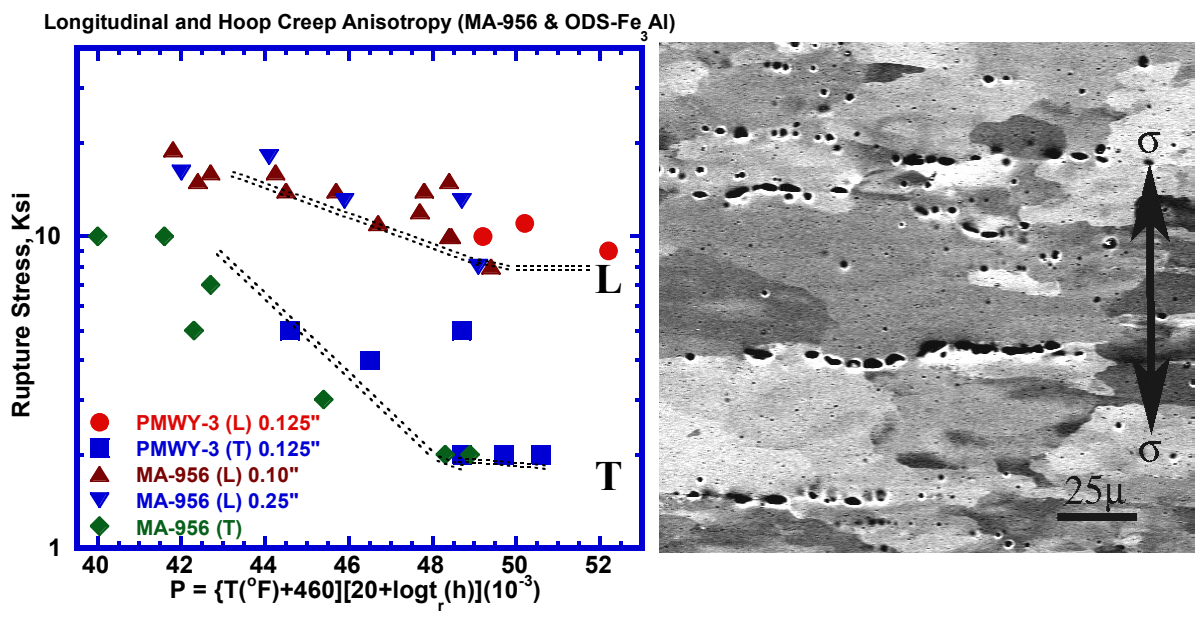

Figure 2. Longitudinal (L) vs. transverse (T) creep anisotropy in $\mathrm{Fe}_{3} \mathrm{Al}$ (PMWY3) and MA-956 tubes._b) Creep cavitation observations in hoop creep loading tests.

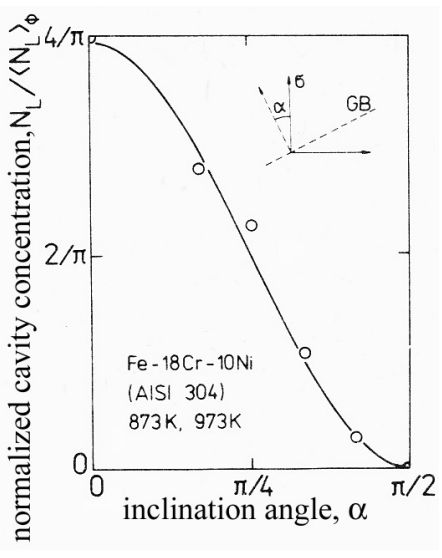

Figure 3. Creep cavity density as $f_{n}(\mathrm{~GB}$ orientation) with respect to the loading axis [7].

Thus, our research objective is to modify tube-processing methodologies by incorporating cross-roll forming to create the underlying microstructure that will meet or exceed the design 'inservice' creep-life requirements of such ODS-alloy heat exchanger tubes. We are examining microscopic, microstructural and morphological issues with a view to addressing optimum material design for macroscopic components for a well prescribed 'in-service' loading criteria. A set of program tasks were outlined in the initial submission and a list of anticipated milestones were submitted to NETL in Fall 2003. This quarterly report summarizes our research activity in the third quarter of performance period of April $1^{\text {st }}-$ June $30^{\text {th }} 2004$.

In the performance period program work was initiated on Tasks 3 and 4 as well as continuing Task 2 . Task 1 was completed in previously and will provide all program materials for the remaining tasks of this program. Task 2 consisting of cross-rolling flat segments of tubes is continuing and will be engaged in iteratively. Samples of both the ODS-Fe $3 \mathrm{Al}$ and FeCrAl (MA956) materials have been flattened at cross-rolled. The ODS-Fe 3 Al tubes are initially 11/4" OD, 1/8" wall thickness and the ODS-FeCrAl tubes are 21/2" OD, 1/4" wall thickness. Three different roll flattening processes are employed as 1) roll-longitudinally, 2) roll transverse to flatten and 3) roll flatten to $20-25 \%$ reduction in thickness. Samples are now being cut in transverse (hoop) orientations for high temperature creep testing. Full details of these creep tests will be reported in the next performance period. 


\section{§ 2. Experimental Task Structure}

The experimental work reported here is described in the context of the task structure outlined below. For the duration of this program activity through September $30^{\text {th }} 2005$ and required reporting (monthly or quarterly) we will refer to this task structure for clarity and precise reference.

Task 1: Extrusion Consolidations, Tube and Sheet Forms: Completed

1.1 ODS-Powder materials - milling studies, impurity evaluation

1.2 Annular ODS-Alloy tube and sheet extrusions

Task 2: Rolling Studies for Optimum Fibering: Initiated \& Continuing

2.1 Single vs. cross-rolling evaluation, Parametric studies

2.2 Correlate cross-rolling strains and overall grain re-orientation

Task 3: Post-Extrusion Cross-Roll Rolling of ODS-tubes \& shells: Initiated \& Continuing

3.1 Helical/cross rolling for grain fibering

3.2 Computer model verification for torsional flow predictions

Task 4: Microstructure and Creep Performance Evaluation: Initiated \& Continuing

4.1 Recrystallization annealing: static and gradient

4.2 Microstructure characterization \& evaluation

4.3 Transverse creep and stress-rupture response

\section{§ 3. Experimental Program Activity}

Task 2.1: Single vs. cross-rolling evaluation, parametric studies: Flat sections of initial uniaxially rolled/extruded coupons to be cross-rolled via parametric evaluations of cross-grain fibering of the underlying grain structure.

Materials produced in Task 1.1 and 1.2 were sectioned and examined for microstructural details. No recrystallization was observed in either alloy materials as a result of this $900^{\circ} \mathrm{C}$ thermal-mechanical treatment. This flattened strip is the required material for the initial matrix of parametric cross-rolling studies. Based on the post-forging microstructural evaluation, and in the interest of narrowing experimental windows, all further cross-rolling studies are to be conducted at $900^{\circ} \mathrm{C}$. Residual curvature in the forge-flattened specimens was eliminated via subsequent rolling as described here. Three separate rolling schemes were employed: 1) Rolling longitudinally in 0.01 " steps till the sample was measurably flat, 2) Rolling transversely to the tube axis in 0.01 " steps till the sample was measurably flat, and 3) Rolling transversely to effect a net $20-25 \%$ thickness reduction in the starting wall thickness. In the rolling schedule 3 , this large deformation was accomplished in steps of 4-5\% reduction per pass with the sample reheated to $900^{\circ} \mathrm{C}$ for 15 minutes in the air furnace. . Additional levels of (cross-rolling) strains 
will be evaluated in the next quarter. The rolled flat samples were removed from their stainless steel wraps and prepared for the recrystallization treatments of Task 4.1.

Task 3: Cross-Roll Rolling: As part of this task UCSD has proposed to purchase and install a used rotary cross-rolling set up for all future cross-rolling operations of MA956 and ODS-Fe3A1 tubes under this program and any future needs. Such equipment when acquired would require significant retrofit and redesign of the rolls to accomplish the tasks at hand.

The PI undertook a series of visits to metalworking machinery dealers in Pittsburgh (PA), Cleveland $(\mathrm{OH})$, Toledo $(\mathrm{OH})$, Perrysburg $(\mathrm{OH})$ and Detroit $(\mathrm{MI})$ to identify possible equipment. It was determined that a 2-roll rotary straightener of the MEDART or MEECO make offers the best possibility of retrofitting to our needs. We also note that the ideal configuration would indeed be an axially aligned 3-roll straightener - but that no such machinery exists in the size range of laboratory scale use. A Medart straightener size ' 0 ' was identified in Pittsburgh and another was identified in an installation in Detroit. Discussions are now under way to acquire either of these machines. We expect the purchase to be finalized in the next performance period.

Task 4.1: Recrystallization Annealing: Recrystallization strategies for creating abnormal grain growth in ODS alloy materials cross-rolled in Task 2.1 (and from Task 3 in later periods) suitable for transverse creep enhancements are listed in Table 1.

\begin{tabular}{|c|c|c|c|c|}
\hline HT Test\# & Material & HT: Temperature, ${ }^{\circ} \mathrm{C}$ & HT: Time, Hrs & Environment \\
\hline 1 & ODS-Fe 3 Al & $1200{ }^{\circ} \mathrm{C}$ & $1 \mathrm{hr}$ & Air \\
\hline 2 & ODS-Fe 3 Al & $1200{ }^{\circ} \mathrm{C}$ & $1 \mathrm{hr}$ & Argon \\
\hline 3 & ODS-MA956 & $1375^{\circ} \mathrm{C}$ & $1 \mathrm{hr}$ & Air \\
\hline 4 & ODS-MA956 & $1375^{\circ} \mathrm{C}$ & $1 \mathrm{hr}$ & Argon \\
\hline 5 & ODS-MA956 & $1400^{\circ} \mathrm{C}$ & $1 \mathrm{hr}$ & Air \\
\hline 6 & ODS-MA956 & $1400^{\circ} \mathrm{C}$ & $1 \mathrm{hr}$ & Argon \\
\hline
\end{tabular}

The heat-treatment temperatures are based on prior DOE funded work performed by the PI. The introduction of inert environment HT was initially applied to ODS-Fe 3 Al alloys, which produced significant improvements in transverse creep. This inert treatment will be applied to ODS-MA956 alloys in the present study. In the current performance period HT tests 1, 2 and 3 have been complete for all cross-rolled materials from Task 2.1. Additional tests 4, 5 and 6 will be conducted later in the program.

Microstructures reveal elongated grain shapes in the transverse orientation only for the sample cross-rolled $20-25 \%$ in the transverse orientation. It is likely that surface layers are affected in rolling schedule 1 and 2 but no changes were perceptible at the level of optical resolution.

\section{Task 4.3: Transverse Creep and Stress Rupture Response:}

The initial cross-rolled samples from Task 2, heat treated in Task 4.1 are spark machined to extract ASTM E-8 standard specimens from the transverse orientation. These are now being being evaluated in transverse (hoop) creep tests and compared to the base line hoop creep behavior of as-extruded tubes. Creep tests have been initiated at a stress of $2 \mathrm{Ksi}$ at $900^{\circ} \mathrm{C}$ in air. 
Two creep tests have currently logged a total of about 670hours of exposure with failure. We expect to continue expanding this creep data set to failure in later performance periods.

\section{$\S$ 4. Results and Discussion}

The experimental program is proceeding at the originally prescribed timetable. The initial material preparation steps are well characterized and known from prior experience. Additional tasks under way will yield much of the preliminary test data for cross-rolling strains necessary for the success of this program.

In the cross-rolling trials we note that significant grain alignment was recorded in the transverse direction, whereas none was observed in rolling schedule \#2 (see section on Task 2.1). It is unknown if lower levels of strain (say for example 10-15\%) will be sufficient to effect some grain organization. This will be examined in the next iteration of cross-rolling studies.

\section{$\S 4$. Conclusions}

The current research program was initiated on October $1^{\text {st }} 2003$ and is just concluding its third quarter of performance. The project progress is on schedule with Task 1 completed and work initiated on each of the remaining tasks 2,3 and 4. MA956 material has been suitably crossrolled in a laboratory rolling mill and is providing the initial data of creep enhancements as a result of cross-rolling induced grain realignment.

\section{References:}

1. F. Starr, in Materials for High-Temperature Power Generation and Process Plant Applications, A. Strang, Ed., IOM Communications Ltd., Book No. 728, pp. 79-152 (2000).

2. V.K. Sikka, I.G. Wright, and B.K. Kad, " Processing of Oxide-Dispersion-Strengthened $\mathrm{Fe}_{3}$ Al-Based Alloy Tube" (1998) $12^{\text {th }}$ Annual Fossil Energy Materials Conf., Knoxville, TN, May 12-14, 1998, p.11-19

3. B.K. Kad, C.G. McKamey, I.G. Wright and V.K. Sikka, "Optimization of ODS-Alloy Properties" (2002) $16^{\text {th }}$ Annual Fossil Energy Materials Conf., Baltimore, MD, April $22^{\text {nd }}-24^{\text {th }}$, 2002.

4. B.K. Kad, C.G. McKamey, I.G. Wright and V.K. Sikka, "High Temperature Mechanical Properties of ODS-Fe 3 Al Tubes" (2001) $15^{\text {th }}$ Annual Fossil Energy Materials Conf., Knoxville, TN, April $30^{\text {th }}$-May $2^{\text {nd }}, 2001$

5. B.K. Kad, V.K. Sikka, R.N. Wright and I.G. Wright, "Oxide Dispersion Strengthened $\mathrm{Fe}_{3} \mathrm{Al}-$ Based Alloy Tubes" (2000) $14^{\text {th }}$ Annual Fossil Energy Materials Conf., Knoxville, TN, April 2426, 2000; ibid (1999) $13^{\text {th }}$ Annual Fossil Energy Materials Conf., Knoxville, TN, May $11^{\text {th }}-14^{\text {t }}$, 1999.

6. J. Ritherdon, A.R. Jones and I.G. Wright, "The Recovery and Recrystallization of a Mechanically Alloyed ODS-Fe 3 Al Alloy" (2001) Materials Science Forum, 360-362, pp.217222, 2001

7. I.W. Chen and A.S. Argon, "Creep Cavitation in 304 Stainless Steel" (1981) Acta Metallurgica, 29, p.1321, 1981; ibid. "Diffusive Growth of Grain-Boundary Cavities" Acta Metallurgica, 29, p1759, 1981 